\title{
Sociodemographic correlates of obesity among Ghanaian women
}

\author{
Fidelia AA Dake*, Emmanuel O Tawiah and Delali M Badasu \\ Regional Institute for Population Studies, University of Ghana, PO Box LG 96, Legon, Accra, Ghana
}

Submitted 16 February 2010: Accepted 3 September 2010: First published online 290 0ctober 2010

\begin{abstract}
Objective: To examine the sociodemographic correlates of obesity among Ghanaian women.

Design: The 2003 and 2008 Ghana Demographic and Health Survey data sets were used to examine the sociodemographic characteristics and the BMI of women aged 15-49 years using descriptive statistics, bivariate and multivariate analyses.

Setting: Ghana is a West African country which is divided into ten administrative regions. The country is further divided into the northern and southern sectors. The northern sector includes the three northern regions (Northern, Upper East and Upper Westen regions) and the seven remaining regions form the southern sector.

Subjects: Women aged 15-49 years whose BMI values were available.

Results: The overall prevalence of obesity and overweight increased from $25.5 \%$ in 2003 to $30.5 \%$ in 2008 . Obesity varied directly with age from 20 to 44 years. Women with higher education had the highest rate of obesity. Obesity was more common among women from wealthy households compared to women from poor households.

Conclusions: Obesity and overweight were found to be more common among older women, urban women, married women, women with higher education and women from rich households. Adoption of healthy lifestyles and the implementation of policies that promote healthy living can help reduce the prevalence of overweight and obesity.
\end{abstract}

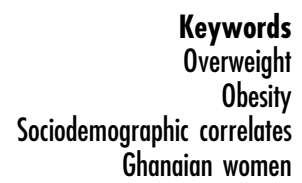

Obesity and overweight, which were once problems of developed countries, have now become a major public health issue in developing countries, particularly in urban areas ${ }^{(1)}$. Poor dietary practices such as consumption of sugary, fatty and energy-dense foods and lack of physical activity are the main causes of obesity and overweight $^{(2-4)}$. There are certain predisposing factors to developing obesity, including age and sex. Other conditions such as the genetic make-up of an individual or the presence of certain medical disorders, such as neuro-endocrine disorders, predispose an individual to being obese ${ }^{(3)}$. The rising prevalence of overweight and obesity poses many challenges for developing countries, the effects of which are most pronounced in the areas of general population health, maternal mortality and national health expenditure.

The rising prevalence of overweight and obesity is associated with a corresponding increase in the prevalence of non-communicable diseases (NCD), which reduces quality of life and also leads to premature death $^{(5)}$. These conditions also decrease the number of healthy years of life (HLY), while increasing the number of disability-adjusted life years (DALY) in a population. In Ghana, the prevalence of obesity rose from as low as
$0 \cdot 9 \%$ in the late 1980 s to about $14 \cdot 1 \%$ in $2003^{(6,7)}$. Obesity is especially more common among Ghanaian women than among men. Prentice ${ }^{(8)}$ (2006) reports that between 1987 and 1989 obesity was six times as common among women as among men. Amoah's ${ }^{(9)}$ study in early 2000 also found that there were higher rates of obesity among women $(20 \cdot 2 \%)$ than men $(4 \cdot 6 \%)$. A survey on NCD conducted in Ghana in 1998 recorded a national hypertension prevalence of $28 \cdot 7 \%{ }^{(9)}$. The cost of controlling one case of diabetes per year in Ghana ranges from GH $\not 1200$ to GH $\not 7200$ (K Amoateng, LK Acheampong, A Addo-Danquah et al., unpublished results). Obesity was found to be a major cause of maternal death in the Korle Bu Teaching Hospital $^{(10)}$ of Ghana in the 1990s. With an already high maternal mortality rate and a rising prevalence of obesity, Ghana faces a difficult challenge of not achieving the Millennium Development Goals in the area of reducing maternal mortality rate by two-thirds by the year 2015 .

In spite of the rising prevalence of obesity in Ghana, research on obesity in Ghana is limited ${ }^{(7,11,12)}$. The present study primarily examines the sociodemographic correlates of obesity among Ghanaian women. The study also aims at identifying groups of women who are at risk of obesity. 


\section{Materials and methods}

\section{Source of data}

The present study uses data from the 2003 and 2008 Ghana Demographic and Health Survey. The demographic and health survey is a nationally representative survey that collects demographic and health data in developing countries over specified time periods. Ghana has conducted this survey every 5 years since 1988. A two-stage stratified sampling design was used to select respondents for the 2003 and 2008 surveys. Respondents for the present study comprise women aged 15-49 years whose weight and height values were available. The sample consisted of 5279 women in 2003 and 4832 women in 2008. Questionnaires were administered to collect sociodemographic information. The weight and height values of the women were used to calculate their BMI.

\section{Dependent variable}

The BMI of the women was used as a measure for the dependent variable. BMI is computed by dividing weight in kilograms by height in metres squared $\left(\mathrm{kg} / \mathrm{m}^{2}\right)^{(3,4,13)}$. The BMI method of determining obesity is independent of sex and is widely accepted for population-level analysis. It is used internationally as the standard of defining overweight and obesity in adult populations ${ }^{(1)}$. In carrying out the present study, the women were grouped into BMI categories, using the standard WHO cut-off points, as underweight $\left(<18.5 \mathrm{~kg} / \mathrm{m}^{2}\right)$, normal weight $(18.5-$ $\left.24.9 \mathrm{~kg} / \mathrm{m}^{2}\right)$, overweight $\left(25 \cdot 0-29 \cdot 9 \mathrm{~kg} / \mathrm{m}^{2}\right)$ and obese $\left(\geq 30 \cdot 0 \mathrm{~kg} / \mathrm{m}^{2}\right)$. Pregnant women and women who had delivered 4 months before the survey were not included in the sample because of weight gain associated with pregnancy and the immediate postpartum period.

\section{Independent variables}

The independent variables used in the present study were the sociodemographic characteristics of the women, namely age, place of residence, region of residence, level of education, ethnicity, religion, occupation, marital status, parity and household wealth quintile. The wealth quintile of the household to which the women belonged was used as a proxy for their socio-economic status. The household wealth quintile was constructed using information on household ownership of a number of consumer items, including a television set, bicycle or car, dwelling characteristics, such as source of drinking water, type of sanitation facilities and type of material used for flooring. Each asset was assigned a weight (factor score) through principal component analysis, and the resulting asset scores were standardised in relation to normal distribution. Each household was assigned a score for each asset and the scores were summed up for each household. The total scores were then divided into quintiles, from 1 (lowest) to 5 (highest) ${ }^{(14)}$. The women were ranked according to the wealth quintile of the household they belonged to.

\section{Methods of analysis}

Each independent variable was cross-tabulated against the dependent variable and the significance of the association was tested using the $\chi^{2}$ test. Cross-tabulations were also performed among the independent variables to find out any relationship existing between the independent variables. Multivariate analysis using multinomial logistic regression was carried out using the enter method. Two models were fitted: the first model considered parity as a confounding variable and therefore parity was used as a single predictor variable. The second model used parity as a predictor variable, while controlling for all the other independent variables. BMI status was used as the dependent variable with normal weight as the reference category for both models. For each of the independent variables, a particular category was used as a reference category. For example, the 15-19-year age group was used as the reference category and the likelihood of all the other age groups being overweight or obese was compared to that of the 15-19-year age group. The change in -2log-likelihood was used to determine the fit of the model. The $R^{2}$ of the model was also determined. The significance of each independent variable in predicting BMI status was determined using the likelihood ratio test, which gives the $P$ value for each of the independent variables in the model. The result of the model was interpreted using the OR, which gives the likelihood of an individual being overweight or obese as opposed to the individual being of normal weight. The likelihood of women in different categories of the independent variables being overweight or obese compared to being in the reference category was reported using the OR. The statistical analysis for the present study was carried out using the SPSS statistical software package version $16 \cdot 0$ (SPSS Inc., Chicago, IL, USA).

\section{Results}

Table 1 indicates that the prevalence of overweight and obesity generally increased with age. The proportion of overweight women increased by about seven percentage points among the 25-29- and the 30-34-year age groups over the 5-year period, while among the 40-44-year-olds the proportion of overweight increased by about six percentage points. Obesity was lowest among women who did not have children compared to women who had children. Ga-Dangme women had the highest percentage of overweight and obese women, whereas Mole-Dagbani women had the lowest. While never married women had the lowest percentage of both overweight and obese women, formerly married women had the highest percentage of overweight women and married women had the highest percentage of obese women. 
Table 1 Distribution of women by sociodemographic characteristics and BMI status

\begin{tabular}{|c|c|c|c|c|}
\hline \multirow[b]{3}{*}{ Variables } & \multicolumn{4}{|c|}{ Percentage in BMl category } \\
\hline & \multicolumn{2}{|l|}{2003} & \multicolumn{2}{|l|}{2008} \\
\hline & Overweight & Obese & Overweight & Obese \\
\hline \multicolumn{5}{|l|}{ Age (years) } \\
\hline $15-19$ & $7 \cdot 2$ & $1 \cdot 0$ & $9 \cdot 0$ & $2 \cdot 0$ \\
\hline $20-24$ & $15 \cdot 1$ & $2 \cdot 6$ & $16 \cdot 6$ & $3 \cdot 1$ \\
\hline $25-29$ & $19 \cdot 5$ & $6 \cdot 4$ & $26 \cdot 7$ & $7 \cdot 4$ \\
\hline $30-34$ & $21 \cdot 7$ & $10 \cdot 8$ & $29 \cdot 2$ & $12 \cdot 6$ \\
\hline $35-39$ & $24 \cdot 9$ & $13 \cdot 1$ & $24 \cdot 5$ & $16 \cdot 8$ \\
\hline $40-44$ & $20 \cdot 1$ & $16 \cdot 4$ & $26 \cdot 5$ & $19 \cdot 8$ \\
\hline $45-49$ & $20 \cdot 1$ & $14 \cdot 0$ & $24 \cdot 8$ & $16 \cdot 7$ \\
\hline \multicolumn{5}{|l|}{ Place of residence } \\
\hline Urban & 23.0 & $12 \cdot 5$ & $26 \cdot 7$ & $14 \cdot 3$ \\
\hline Rural & $12 \cdot 8$ & $3 \cdot 5$ & $15 \cdot 8$ & $4 \cdot 8$ \\
\hline \multicolumn{5}{|l|}{ Region of residence } \\
\hline Western & $19 \cdot 3$ & $6 \cdot 3$ & $24 \cdot 8$ & $9 \cdot 2$ \\
\hline Central & $20 \cdot 1$ & $6 \cdot 1$ & $24 \cdot 2$ & $7 \cdot 7$ \\
\hline Greater Accra & $29 \cdot 5$ & $17 \cdot 3$ & $25 \cdot 8$ & $20 \cdot 8$ \\
\hline Volta & $13 \cdot 1$ & $6 \cdot 6$ & $18 \cdot 6$ & $8 \cdot 3$ \\
\hline Eastern & $17 \cdot 8$ & $7 \cdot 4$ & $25 \cdot 5$ & $9 \cdot 7$ \\
\hline Ashanti & $18 \cdot 7$ & $8 \cdot 7$ & $23 \cdot 7$ & $8 \cdot 4$ \\
\hline Brong Ahafo & $13 \cdot 9$ & $5 \cdot 8$ & $15 \cdot 9$ & $4 \cdot 0$ \\
\hline Northern & $6 \cdot 2$ & 0.9 & $10 \cdot 9$ & $2 \cdot 6$ \\
\hline Upper East & $7 \cdot 7$ & $0 \cdot 4$ & $11 \cdot 8$ & $3 \cdot 8$ \\
\hline Upper West & $5 \cdot 8$ & $1 \cdot 4$ & $9 \cdot 9$ & $2 \cdot 5$ \\
\hline \multicolumn{5}{|l|}{ Level of education } \\
\hline No education & $12 \cdot 3$ & $4 \cdot 4$ & $15 \cdot 2$ & $5 \cdot 2$ \\
\hline Primary & $17 \cdot 4$ & $6 \cdot 9$ & $21 \cdot 5$ & $8 \cdot 8$ \\
\hline Secondary & $20 \cdot 1$ & $9 \cdot 5$ & $22 \cdot 2$ & $10 \cdot 5$ \\
\hline Higher & $30 \cdot 7$ & $19 \cdot 3$ & $36 \cdot 0$ & $19 \cdot 4$ \\
\hline \multicolumn{5}{|l|}{ Ethnicity } \\
\hline Akan & $19 \cdot 5$ & $8 \cdot 0$ & $24 \cdot 0$ & $9 \cdot 9$ \\
\hline Ga-Dangme & $25 \cdot 0$ & $13 \cdot 7$ & $25 \cdot 0$ & $14 \cdot 9$ \\
\hline Ewe & $17 \cdot 8$ & $8 \cdot 6$ & $20 \cdot 1$ & $12 \cdot 9$ \\
\hline Mole-Dagbani & $10 \cdot 2$ & $2 \cdot 6$ & $14 \cdot 9$ & $4 \cdot 3$ \\
\hline Other & $13 \cdot 3$ & $7 \cdot 1$ & $16 \cdot 6$ & $7 \cdot 4$ \\
\hline \multicolumn{5}{|l|}{ Religion } \\
\hline Roman Catholic & $16 \cdot 6$ & $5 \cdot 6$ & $19 \cdot 1$ & $9 \cdot 2$ \\
\hline Orthodox Christian & $18 \cdot 6$ & $10 \cdot 5$ & $23 \cdot 1$ & $10 \cdot \overline{7}$ \\
\hline Other Christian & $20 \cdot 1$ & $8 \cdot 6$ & $22 \cdot 7$ & $10 \cdot 1$ \\
\hline Moslem & $14 \cdot 9$ & $7 \cdot 3$ & $17 \cdot 3$ & $8 \cdot 0$ \\
\hline Other & $7 \cdot 8$ & $0 \cdot 8$ & $16 \cdot 4$ & $4 \cdot 2$ \\
\hline \multicolumn{5}{|l|}{ Occupation } \\
\hline Not working & $19 \cdot 9$ & $4 \cdot 5$ & $12 \cdot 7$ & $5 \cdot 0$ \\
\hline Formally employed & $28 \cdot 7$ & $20 \cdot 2$ & $31 \cdot 7$ & $13 \cdot 8$ \\
\hline Sales/services & $26 \cdot 1$ & $12 \cdot 8$ & $29 \cdot 1$ & $15 \cdot 1$ \\
\hline Agric-self employed & $11 \cdot 0$ & $2 \cdot 8$ & $13 \cdot 6$ & $3 \cdot 7$ \\
\hline Unskilled/skilled & $18 \cdot 2$ & $8 \cdot 7$ & $20 \cdot 9$ & $7 \cdot 8$ \\
\hline \multicolumn{5}{|l|}{ Marital status } \\
\hline Never married & $10 \cdot 9$ & $1 \cdot 9$ & $15 \cdot 1$ & $3 \cdot 2$ \\
\hline Married & $20 \cdot 0$ & $4 \cdot 0$ & $24 \cdot 1$ & $13 \cdot 4$ \\
\hline Living together & $18 \cdot 6$ & $13 \cdot 0$ & $21 \cdot 9$ & $6 \cdot 7$ \\
\hline Formerly married & $23 \cdot 0$ & $7 \cdot 8$ & $26 \cdot 0$ & $9 \cdot 4$ \\
\hline \multicolumn{5}{|l|}{ Wealth status } \\
\hline Poorest & $7 \cdot 7$ & $1 \cdot 4$ & $9 \cdot 7$ & $2 \cdot 2$ \\
\hline Poorer & $10 \cdot 8$ & $2 \cdot 3$ & $13 \cdot 2$ & $3 \cdot 3$ \\
\hline Average & $14 \cdot 9$ & $4 \cdot 0$ & $19 \cdot 1$ & $5 \cdot 1$ \\
\hline Richer & $21 \cdot 2$ & 8.9 & $29 \cdot 8$ & 11.9 \\
\hline Richest & $28 \cdot 3$ & $17 \cdot 9$ & $28 \cdot 1$ & $20 \cdot 3$ \\
\hline \multicolumn{5}{|l|}{ Parity } \\
\hline 0 & $12 \cdot 7$ & $3 \cdot 0$ & $15 \cdot 6$ & $4 \cdot 5$ \\
\hline $1-3$ & $20 \cdot 5$ & $9 \cdot 6$ & $24 \cdot 3$ & $11 \cdot 2$ \\
\hline $4-6$ & $20 \cdot 2$ & $10 \cdot 8$ & $23 \cdot 6$ & $14 \cdot 3$ \\
\hline$\geq 7$ & $16 \cdot 8$ & $9 \cdot 5$ & $22 \cdot 6$ & $8 \cdot 6$ \\
\hline Total & $17 \cdot 7$ & $7 \cdot 8$ & $21 \cdot 1$ & $9 \cdot 4$ \\
\hline
\end{tabular}

Overweight and obesity were more common in urban areas than in rural areas. Over the 5-year period, overweight increased by almost four and three percentage points, respectively, among urban and rural women. Southern Ghana recorded a higher prevalence of overweight and obesity compared to northern Ghana. The prevalence of overweight increased by almost four percentage points in the three northern regions while obesity, which was practically absent in 2003 , showed a prevalence of at least $2 \cdot 5 \%$ in 2008. The prevalence of overweight and obesity generally increased with increasing level of education. Women with higher education remained predominantly overweight or obese while women with no education had the lowest rate of overweight and obesity. Women in formal employment and sales/service personnel were more likely to be overweight or obese compared to those who worked as agricself-employed women. Overweight and obesity increased with the increasing wealth quintile. Women in the richer wealth quintile category were more likely to be overweight or obese, whereas those in the poorer wealth quintile category were less likely to be overweight or obese.

The results in Table 2 indicate that the likelihood of a woman being overweight or obese increased with increasing age; older women were thus more likely to be overweight or obese compared to the youngest age group. In 2003, women who resided in regions other than the Greater Accra region were less likely to be overweight or obese, whereas in 2008, women from the Eastern region had a $42 \%$ higher chance of being overweight compared to those from the Greater Accra region. Women who had higher education were about two times more likely to be overweight compared to non-educated women. Women from richer households were twice as likely to be overweight and about five times as likely to be obese compared to women from households of average wealth status.

\section{Discussion}

Parity as a single predictor of obesity was significant in predicting obesity. This can be attributed to weight gain associated with pregnancy and child birth and also weight retention with each subsequent birth ${ }^{(15)}$. Obesogenic cultures associated with pregnancy and childbirth further compound the risk of obesity among women in subSaharan Africa. In Ghana, some women report that traditional breast milk-inducing foods, such as palm-nut soup, are fattening. Consumption of such foods constitutes an obesogenic risk for women of childbearing age ${ }^{(16)}$. Kin support and care for the new mother during the immediate postpartum period also constitute a risk factor for obesity because of reduced physical activity levels during this period.

Africa is noted to be typically pro-natalist, and in many parts of Africa large families are still the norm ${ }^{(17)}$. Ghana's total fertility rate was $4 \cdot 4$ and $4 \cdot 0$ in 2003 and $2008^{(14,18)}$, 
Table 2 Results of multinomial logistic regression of sociodemographic determinants of obesity among Ghanaian women

\begin{tabular}{|c|c|c|c|c|}
\hline \multirow[b]{3}{*}{ Variables } & \multicolumn{4}{|c|}{ Likelihood of a woman being overweight or obese (OR) } \\
\hline & \multicolumn{2}{|c|}{2003} & \multicolumn{2}{|c|}{2008} \\
\hline & Overweight & Obese & Overweight & Obese \\
\hline \multicolumn{5}{|l|}{ Age (years) } \\
\hline 15-19 (Ref.) & $1 \cdot 000$ & $1 \cdot 000$ & $1 \cdot 000$ & $1 \cdot 000$ \\
\hline $20-24$ & $1 \cdot 748^{\star *}$ & 1.666 & $1 \cdot 497^{\star}$ & $1 \cdot 180$ \\
\hline $25-29$ & $2 \cdot 441^{\star \star \star}$ & $3 \cdot 989^{\star \star}$ & $2 \cdot 825^{\star \star \star}$ & $2 \cdot 939^{\star *}$ \\
\hline $30-34$ & $3 \cdot 115^{\star \star \star}$ & $7 \cdot 667^{\star \star \star}$ & $3 \cdot 496^{\star \star \star}$ & $4 \cdot 963^{\star * *}$ \\
\hline $35-39$ & $4 \cdot 324^{\star \star \star}$ & $11 \cdot 138^{\star \star \star}$ & $3 \cdot 122^{\star \star \star}$ & $7 \cdot 608^{\star \star \star}$ \\
\hline $40-44$ & $3 \cdot 911^{\star \star *}$ & $13 \cdot 108^{\star \star \star}$ & $4 \cdot 073^{\star \star \star}$ & $10 \cdot 947^{\star \star *}$ \\
\hline $45-49$ & $3 \cdot 735^{\star \star *}$ & $12 \cdot 602^{\star \star \star}$ & $3 \cdot 189^{\star \star \star}$ & $8 \cdot 135^{\star \star \star}$ \\
\hline \multicolumn{5}{|l|}{ Place of residence } \\
\hline Urban & $1 \cdot 018$ & $1 \cdot 321$ & $1 \cdot 259^{*}$ & $1 \cdot 373^{*}$ \\
\hline Rural (Ref.) & $1 \cdot 000$ & $1 \cdot 000$ & $1 \cdot 000$ & $1 \cdot 000$ \\
\hline \multicolumn{5}{|l|}{ Region of residence } \\
\hline Western & 0.818 & 0.733 & $1 \cdot 220$ & 0.692 \\
\hline Central & $0 \cdot 830$ & $0 \cdot 805$ & $1 \cdot 295$ & 0.717 \\
\hline Greater-Accra (Ref.) & 1.000 & $1 \cdot 000$ & $1 \cdot 000$ & $1 \cdot 000$ \\
\hline Volta & $0 \cdot 488^{\star \star \star}$ & 0.697 & $1 \cdot 101$ & 0.765 \\
\hline Eastern & $0 \cdot 606^{* *}$ & $0 \cdot 644^{*}$ & $1 \cdot 417^{\star}$ & 0.939 \\
\hline Ashanti & $0.642^{\star *}$ & 0.694 & 1.094 & $0 \cdot 646^{\star}$ \\
\hline Brong Ahafo & $0 \cdot 515^{\star \star *}$ & 0.590 & 0.699 & $0 \cdot 350^{\star \star *}$ \\
\hline Northern & $0 \cdot 191^{* \star *}$ & $0.072^{\star \star \star}$ & $0 \cdot 606^{*}$ & $0 \cdot 368^{\star \star}$ \\
\hline Upper East & $0 \cdot 204^{\star \star \star}$ & $0 \cdot 145^{\star}$ & $0 \cdot 708$ & 0.646 \\
\hline Upper West & $0 \cdot 326^{\star \star *}$ & $0.051^{* *}$ & 0.545 & $0 \cdot 380$ \\
\hline \multicolumn{5}{|l|}{ Level of education } \\
\hline No education (Ref.) & $1 \cdot 000$ & $1 \cdot 000$ & $1 \cdot 000$ & $1 \cdot 000$ \\
\hline Primary & $1 \cdot 269$ & $1 \cdot 380$ & $1 \cdot 420^{\star}$ & $1 \cdot 578^{*}$ \\
\hline Secondary & $1 \cdot 202$ & $1 \cdot 247$ & $1 \cdot 347^{\star}$ & $1 \cdot 558^{*}$ \\
\hline Higher & $1 \cdot 750^{\star}$ & 1.909 & $2 \cdot 025^{\star \star}$ & $2 \cdot 700^{\star *}$ \\
\hline \multicolumn{5}{|l|}{ Ethnicity } \\
\hline Akan (Ref.) & $1 \cdot 000$ & $1 \cdot 000$ & $1 \cdot 000$ & $1 \cdot 000$ \\
\hline Ga-Dangme & $1 \cdot 225$ & $1 \cdot 486$ & $1 \cdot 135$ & $1 \cdot 226$ \\
\hline Ewe & $1 \cdot 083$ & $1 \cdot 184$ & 0.997 & $1 \cdot 507^{\star}$ \\
\hline Mole-Dagbani & $1 \cdot 180$ & $1 \cdot 065$ & $1 \cdot 074$ & 0.629 \\
\hline Other & 0.938 & $1 \cdot 126$ & $1 \cdot 029$ & $1 \cdot 013$ \\
\hline \multicolumn{5}{|l|}{ Religion } \\
\hline Roman Catholic & 1.074 & 0.968 & $1 \cdot 167$ & $1 \cdot 508^{*}$ \\
\hline Orthodox Christian & 0.902 & $1 \cdot 127$ & $1 \cdot 106$ & $1 \cdot 241$ \\
\hline Other Christian (Ref.) & $1 \cdot 000$ & $1 \cdot 000$ & $1 \cdot 000$ & $1 \cdot 000$ \\
\hline Moslem & $1 \cdot 188$ & $1 \cdot 479$ & $1 \cdot 119$ & $1 \cdot 662$ \\
\hline Other & 0.667 & $0 \cdot 205^{\star}$ & $1 \cdot 246$ & 0.932 \\
\hline \multicolumn{5}{|l|}{ Occupation } \\
\hline Not working (Ref.) & $1 \cdot 000$ & $1 \cdot 000$ & $1 \cdot 000$ & $1 \cdot 000$ \\
\hline Formally employed & 0.938 & 0.796 & $1 \cdot 291$ & $0 \cdot 761$ \\
\hline Sales/services & $1 \cdot 225$ & 0.911 & $1 \cdot 663^{\star \star \star}$ & $1 \cdot 428$ \\
\hline Agric-self employed & $0.639^{* *}$ & $0 \cdot 343^{\star * \star}$ & $1 \cdot 218$ & 0.835 \\
\hline Unskilled/skilled & $0 \cdot 817$ & 0.650 & $1 \cdot 107$ & $0 \cdot 744$ \\
\hline \multicolumn{5}{|l|}{ Wealth status } \\
\hline Poorest & 0.767 & 0.764 & $0 \cdot 655^{\star}$ & 0.690 \\
\hline Poorer & $0 \cdot 737^{\star}$ & 0.670 & $0 \cdot 730^{\star}$ & 0.773 \\
\hline Average (Ref.) & $1 \cdot 000$ & $1 \cdot 000$ & $1 \cdot 000$ & $1 \cdot 000$ \\
\hline Rich & $1 \cdot 438^{\star *}$ & $2 \cdot 044^{\star \star}$ & $2 \cdot 030^{\star \star \star}$ & $2 \cdot 974^{\star \star \star}$ \\
\hline Richer & $2 \cdot 275^{\star \star \star}$ & $4 \cdot 585^{\star \star \star}$ & $2 \cdot 116^{\star \star \star}$ & $5 \cdot 156^{\star \star \star}$ \\
\hline \multicolumn{5}{|l|}{ Marital status } \\
\hline Never married (Ref.) & $1 \cdot 000$ & $1 \cdot 000$ & $1 \cdot 000$ & $1 \cdot 000$ \\
\hline Married & $2 \cdot 617^{\star \star \star}$ & $4 \cdot 826^{\star \star \star}$ & $1 \cdot 120$ & $2 \cdot 289^{\star \star}$ \\
\hline Living together & $1 \cdot 930^{\star \star \star}$ & $2 \cdot 911^{\star \star}$ & $1 \cdot 050$ & $1 \cdot 846^{\star}$ \\
\hline Formerly married & $2 \cdot 171^{\star \star \star}$ & $2 \cdot 624^{\star \star}$ & $1 \cdot 155$ & $2 \cdot 469^{\star \star}$ \\
\hline \multicolumn{5}{|l|}{ Parity } \\
\hline 0 (Ref.) & $1 \cdot 000$ & $1 \cdot 000$ & $1 \cdot 000$ & $1 \cdot 000$ \\
\hline $1-3$ & $0 \cdot 851$ & 0.993 & $1 \cdot 088$ & 0.967 \\
\hline $4-6$ & $0 \cdot 817$ & $1 \cdot 010$ & $1 \cdot 107$ & $1 \cdot 117$ \\
\hline$\geq 7$ & 0.818 & $1 \cdot 267$ & $1 \cdot 376$ & $1 \cdot 132$ \\
\hline & Nagelkerke $R^{2}=$ & $=0.000,67.0 t$ & Nagelkerke $R^{2}=$ & $=0.000,63.5 t$ \\
\hline
\end{tabular}

Ref., reference category.

${ }^{\star} P<0.05,{ }^{\star \star} P<0.01,{ }^{\star * \star} P<0.001$.

tOverall percentage of BMI correctly predicted. 


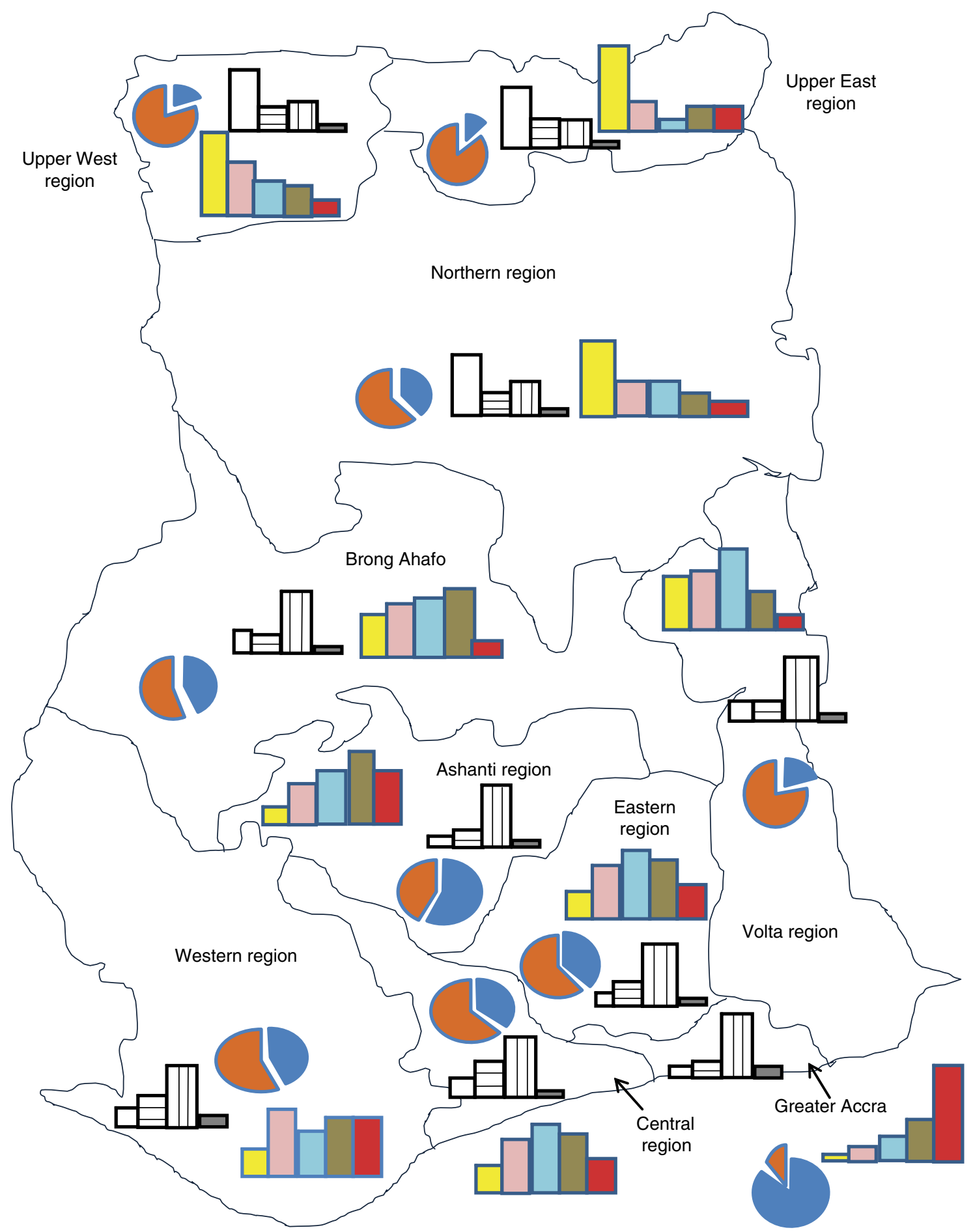

Fig. 1 Map of Ghana showing regional distribution of wealth status ( $\square$, poorest; $\square$, poorer; $\square$, middle; $\square$, richer; $\quad$, richest), level of education ( $\square$, no education;, , primary; $\square$, secondary; $\square$, higher) and place of residence ( $\checkmark$, rural; $\square$, urban). Source: generated using data from the Ghana Demographic and Health Survey, 2008

respectively. This means that a Ghanaian woman will have four children on average by the time she reaches the end of her reproductive years if she conforms to the existing age-specific fertility rates. Almost a third $(31 \cdot 6 \%)$ of the women involved in the present study had four or more children. After controlling for the other variables parity was not significant in predicting obesity, which contradicts the findings of other studies that revealed that parity had a significant influence on obesity ${ }^{(15,19)}$. This finding also suggests that parity, together with other factors, such as dietary and obesogenic cultural practices constitute risk factors for obesity among Ghanaian women. 
In most African cultures, a fat woman is seen as beautiful. This is because fatness is associated with wealth, health and prestige ${ }^{(20)}$. Being married has also been found to be associated with overweight and obesity, especially among African women. Research in Ghana, however, indicates that this perception is slowly changing ${ }^{(21)}$. The results of the present study indicate that married women were more likely to be overweight or obese and this is probably because of the socio-cultural perception about fatness being associated with beauty especially among married women. The findings of the present study are consistent with those of other studies $^{(7,22)}$.

Older women in the present study were more likely to be overweight or obese. This finding is consistent with those of other studies conducted in Ghana ${ }^{(7,11,12)}$. The study reveals a rise in the prevalence of overweight and obesity among women in the northern sector of Ghana, which raises a number of concerns. The results indicate that about $45 \%$ of women resident in each of the three northern regions were agric-self-employed women. Other activities carried out by women in these regions include walking over long distances to fetch water or firewood $^{(23)}$. These women expended a lot of energy in carrying out these activities. Again, the three northern regions are the poorest regions in Ghana ${ }^{(23)}$ and they are also predominantly rural. Northern Ghana thus has less of a problem with nutritional transition, which is more common in urban areas (Fig. 1).

The results of the present study show that at least $60 \%$ of women in the three northern regions belong to poor households. Several studies have found a reverse relationship between socio-economic status and the risk of obesity ${ }^{(24,25)}$. These studies reveal that the poor in deprived and low-status areas consume more cheap food items, such as refined carbohydrates, polished grains and frozen meat products. Globalisation, trade liberalisation and open-market economies have aided the availability of such food items in deprived communities. Consumption of such food items is reported to contribute to the incidence of obesity because of their high energy value. This low socio-economic status/obesity link could be the possible explanation for the rising prevalence of obesity and overweight among women in the three northern regions. Further research needs to be carried out to establish the factors that are responsible for the rising prevalence of obesity in northern Ghana.

In southern Ghana, women in the Greater Accra region had the highest prevalence of obesity and overweight with almost one in two of them being either overweight or obese. The Greater Accra region is the most urbanised region in Ghana. Rapid rates of urbanisation in urban areas such as Accra, coupled with the Westernisation of diets, has led to the consumption of more fried, fatty and sugary foods. These foods have a high energy value and their consumption contributes to overweight and obesity. People in urban areas are also more likely to own cars and to board vehicles rather than walk even over short distances and this has resulted in reduced physical activity levels in urban areas compared to rural areas where people walk over long distances to the farm or to fetch water. Rapid rates of urbanisation have also been characterised by densely populated urban areas and other problems such as vehicular traffic congestion. People in most urban areas thus spend long hours in traffic and this has also contributed to physical inactivity. These lifestyle behaviours associated with living in urban areas contribute to the increasing prevalence of obesity and overweight in urban areas.

The present study used multinomial logistic regression modelling because the dependent variable was treated as a categorical variable with four different categories. This procedure assumes that there is no ranking or ordering in the categorical dependent variable and it also compares the estimates for each category of the dependent variable to the reference. The overall model of significance for the models $(P<0 \cdot 001)$ and the percentage of the dependent variable correctly predicted show that the model fits the data structure well and also give an indication that the model was a good fit. The limitations of the present study should be noted when reporting the results. The study uses secondary data from the demographic and health survey; the limitations of those data therefore apply to the present study as well. For example, most postpartum weight retention studies measure weight at 12 months after delivery and this makes comparison to these studies more difficult. Data on the dietary practices and the physical activity levels of the women were not available; therefore, these variables were not included in the analysis. Including these variables in the analysis could have given slightly different results or could have made certain patterns that were observed more clear.

\section{Conclusion}

In 2003, approximately one-quarter (25.5\%) of Ghanaian women were either overweight or obese and this proportion increased to a little under one-third (30.5\%) in 2008 , indicating a five-percentage point increase in the prevalence of unhealthy weight among Ghanaian women over the 5-year period. The likelihood ratio tests showed that age, region of residence, level of education, occupation, wealth status and marital status are significant predictors of obesity. Obesity and overweight were found to be more common among older women, urban women, women with higher education and women from wealthy households. The study revealed that not only has the prevalence of overweight and obesity increased among Ghanaian women, but also prevalence levels have increased among all subgroups.

Educational campaigns on the causes and health implications of obesity can help create the needed awareness of obesity in the population and this can help 
stimulate the adoption of healthy lifestyle behaviours such as exercising and eating healthy foods. Programmes such as the Regenerative Health and Nutrition Programme, which seek to encourage healthy lifestyle behaviours, can be encouraged through the use of local drama, which can be aired in the local languages to ensure coverage to the entire population. Appropriate food policies, such as the ban on the importation of turkey tails, because of its harmful health effects, should be strengthened by the Ghanaian government. The existing cultural environment should also be taken into consideration when adopting and implementing policies that target obesity.

\section{Acknowledgements}

The present study received no specific grant from any public agency in public, commercial or not-for-profit sectors. The authors have no conflicts of interest to declare. F.A.A.D. carried out the statistical analysis and prepared the first draft of manuscript; E.O.T. provided comments and made revisions to the first draft of the manuscript and approved the final manuscript; D.M.B. read and approved the final manuscript. The authors thank Dr Ama de-Graft Aikins for her support and encouragement in carrying out the present study.

\section{References}

1. World Health Organization (2006) Obesity and overweight. http://www.who.int/mediacentre/factsheets/fs311/en/ (accessed October 2008).

2. Guthrine HA (1967) Introductory Nutrition. St Louis, MO: The CV Mosby Company.

3. Hill JO, Catenacci VA \& Wyatt RH (2006) Obesity Etiology in Modern Nutrition in Health and Disease, 10th ed., pp. 1013-1016. Philadelphia, PA: Lippincott William and Wilkins.

4. World Health Organization (2000) Obesity: Preventing and Managing The Global Epidemic. WHO Technical Report Series no. 894. Geneva: WHO.

5. Ziraba AK, Fotso CJ \& Ochako R (2009) Overweight and obesity in urban Africa: a problem of the rich or poor? BMC Public Health 9, 465.

6. Berios X, Koponen T, Huiguang T et al. (1997) Distribution and prevalence of major risk factors of non-communicable diseases in selected countries: the WHO Inter-Health Programme. Bull World Health Organ 75, 99-108.

7. Amoah GBA (2003) Socio-demographic variations in obesity among Ghanaian adults. Public Health Nutr 6, 751-757.

8. Prentice MA (2006) The emerging epidemic of obesity in developing countries. Int J Epidemiol 35, 93-99.
9. Amoah AGB, Owusu KO \& Adjei S (2002) Diabetes in Ghana: a community prevalence study in Greater Accra. Diabetes Res Clin Pract 56, 197-205.

10. Lessey AT \& Wilson JB (1998) Trends in maternal mortality in Korle Bu Hospital, 1984-1994. Ghana Med J 32a, 910-916.

11. Biritwum RB, Gyapong J \& Mensah G (2005) The epidemiology of obesity in Ghana. Ghana Med J39, 82-85.

12. Duda RB, Darko R, Seffah J et al. (2007) Prevalence of obesity in women of Accra, Ghana. Afr J Health Sci 14, 154-159.

13. World Health Organization (2004) Obesity and overweight, Fact sheet. http://www.who.org/Papers/Obesity/WHO Obesity and overweight.htm (accessed August 2008).

14. Ghana Statistical Service, Noguchi Memorial Institute for Medical Research \& ORC Macro (2004) Ghana Demographic and Health Survey 2003. Accra, Ghana, Calverton, MD: GSS, NMIMR and ORC Macro.

15. Holdsworth M, Gartner A, Landias E et al. (2004) Perceptions of healthy and desirable body size in urban Senegalese women. Int J Obes 28, 561-1568.

16. de-Graft Aikins A (2010) Culture, diet and the maternal body: Ghanaian women's perspective on food, fat and childbearing. In Fatness and the Maternal Body: Women's Experiences of Corporeality and the Shaping of Social Policy [ $\mathrm{M}$ Unnithan-Kumar and $\mathrm{S}$ Tremayne, editors]. Oxford: Berghahn Books (In the Press).

17. Weeks RJ (1999) Population an Introduction to Concepts and Issues, 7th ed., p. 200. Belmont, CA: Wadsworth Publishing Company.

18. Ghana Statistical Service, Ghana Health Service \& ORC Macro (2009) Ghana Demographic and Health Survey 2008. Accra, Ghana and Calverton, MD: GSS, GHS and ORC Macro.

19. Batnitzky A (2008) Obesity and household roles: gender and social class in morocco. Sociol Health Ill 30, 458-461.

20. Steyn K \& Damasceno A (2006) Lifestyle and related risk factors for chronic diseases. In Disease and Mortality in Sub-Saharan Africa, pp. 247-264 [DT Jamison, RG Feachem, WM Makogoba et al., editors]. Washington, DC: The World Bank.

21. Duda RB, Jumah NA, Hill GA et al. (2006) Interest in healthy living outweighs presumed cultural norms for obesity for Ghanaian women. BMC Health Qual Life Outcomes $\mathbf{4}, 44$.

22. Rguibi M \& Belahsen R (2004) Overweight and obesity among urban Sahraoui women of South Morocco. Ethn Dis 14, 542-547.

23. United Nations Population Fund (2008) Cultural Sensitivity and Programming: The Case of Government of GhanaUNFPA 5th Country Programme 2006-2010. Accra, Ghana: UNPFA.

24. Monteiro CA, Moura CE, Conde LW et al. (2004) Socioeconomic status and obesity in adult populations of developing countries: a review. Bull World Health Organ 82, 940-943.

25. Stunkard AJ (1996) Socio-economic status and obesity. Ciba Symp 201, 174-182. 